\title{
Effects of cadmium and of YAP1 and CAD1/YAP2 genes on iron metabolism in the yeast Saccharomyces cerevisiae
}

\author{
Emmanuel Lesuisse and Pierre Labbe
}

Laboratoire de Biochimie des Porphyrines, Institut J. Monod, Tour 43,

Université Paris 7, 2 Place Jussieu, 75251 Paris cedex 05, France

\author{
Author for correspondence: Emmanuel Lesuisse. Tel: +33143540479. Fax: +33144275716. \\ e-mail: elu@ccr.jussieu.fr
}

\begin{abstract}
Saccharomyces cerevisiae was more resistant to cadmium when the growth medium contained excess iron. Cadmium reduced the amount of iron taken up by cells during growth, and the cell ferrireductase activity was also strongly inhibited. These effects depended on the YAP1 and CAD1/YAP2 gene dosage. The growth rate of cells in iron-deficient conditions and their ferrireductase activity in the absence of added cadmium were also strongly affected by the dosage of YAP1 and CAD1/YAP2 genes. Our results suggest an indirect influence of these genes on iron metabolism, possibly via modification of the cell redox status.
\end{abstract}

Keywords: iron metabolism, cadmium toxicity, ferrireductase, Saccharomyces cerevisiae, $Y A P 1 / C A D 1 / Y A P 2$

\section{INTRODUCTION}

The Saccbaromyces cerevisiae proteins yAP1 and CAD1 (yAP2) are transcription factors that are related to the mammalian proto-oncoproteins c-jun (Moye-Rowley et al., 1989; Bossier et al., 1993; Wu et al., 1993). Harshman et al. (1988) showed that the transcription of genes preceded by the ARE (AP1 recognition element) consensus sequence is activated by yAP1. Several phenotypes associated with the disruption of $Y A P 1$ and $C A D 1 /$ $Y A P 2$ have been described. For example, $\Delta y a p 1$ mutants are more sensitive than their wild-type to cadmium and zinc (Wu et al., 1993) and to oxidative agents (Schnell \& Entian, 1991). Overexpression of $Y A P 1$ causes cells to acquire a pleiotropic drug-resistance phenotype and to become resistant to cadmium. This last phenotype is also observed when CAD1 is overexpressed, but $\Delta$ cad1 mutants are not hypersensitive to this metal (Bossier et al., 1993). Other data also suggest that the YAP1 and $C A D 1$ genes could be involved in the regulation of iron metabolism. Overexpression of $Y A P 1$ or $C A D 1$ confers resistance to the iron/zinc chelator 1,10 phenanthroline (Bossier et al., 1993; Schnell \& Entian, 1991). Addition of iron (but not zinc or copper) alleviates the growth inhibition of a $\Delta y a p 1$ mutant in alkaline medium (Schnell \& Entian, 1991). Bossier et al. (1993) suggested that yAP1 and CAD1/yAP2 promote the production of a secreted

Abbreviations: ARE, AP1 recognition element; BPS, bathophenanthroline disulfonic acid; DTNB, 5,5'-dithio-bis(2-nitrobenzoate). compound that competes with 1,10 phenanthroline for zinc or iron, but this proposition is unrealistic for iron, since $S$. cerevisiae produces no siderophore, and the potential iron-chelating compounds excreted by this yeast [(3-hydroxy)anthranilate and Krebs cycle intermediates; Lesuisse et al., 1992] form complexes with iron that are thermodynamically less stable (low $\mathrm{Kf}$ ) than the ironorthophenanthroline complex.

Iron uptake by $S$. cerevisiae is a two-step process, involving extracellular reduction of ferric complexes by an inducible plasma-membrane-bound reductase (Lesuisse et al., 1987; Dancis et al., 1990), and transport of the free ferrous ions by a high-affinity transport system (Eide et al., 1992). The ferrireductase activity of $S$. cerevisiae depends on at least two genes, FRE1 (Dancis et al., 1992) and FRE2 (Georgatsou \& Alexandraki, 1994), both of which are transcriptionally regulated by iron. Both genes also have ARE $[(G)$ T G A C T C/A A]-resembling elements in their promoter regions (see Discussion). The yAP1 and CAD1 proteins have cysteine-rich $\mathrm{C}$-terminal regions, which make them good potential candidates for playing a role in metal-dependent regulation of transcription. Gounalaki \& Thireos (1994) suggested that there could be direct or indirect interactions between yAP1 and the MAC1 protein, a transcription factor involved in the basal transcription of FRE1 (Jungmann et al., 1993). Previous work suggested that the ferrireductase activity of cells depends on their redox status (Lesuisse \& Labbe, 1992). Cadmium tolerance itself probably depends on the redox status of the cells, since fungi frequently neutralize this 
metal by binding it to glutathione or glutathione polymers. In this context, it could be significant that $\Delta y a p 1$ mutants are hypersensitive to both oxidative stress and to cadmium. Similarly, the loss-of-function mutants of $M A C 1$ are deficient in ferrireductase activity and hypersensitive to $\mathrm{H}_{2} \mathrm{O}_{2}$ and cadmium. The last phenotype is blocked by adding excess iron (Jungmann et al., 1993).

The present paper describes the links between $Y A P 1$ and $C A D 1 / Y A P 2$ genes, iron metabolism and cadmium tolerance in $S$. cerevisiae.

\section{METHODS}

Yeast strains and plasmids. Strains SEY6210 (wild-type),

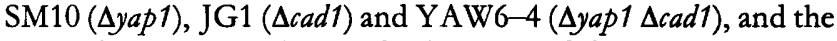
plasmids YEp351-YAP1 and pAW18 used for overexpression in the wild-type strain of $Y A P 1$ and $C A D 1$, respectively, were kindly provided by Dr W. S. Moye-Rowley, Department of Physiology and Biophysics, University of Iowa, IA, USA. The genotypes of these strains and descriptions of the plasmids have been previously published (Wu et al., 1993). The plasmids carrying the FRE1-lacZ fusion were a gift from $\mathrm{Dr}$ R. LabbeBois, Laboratoire de Biochimie des Porphyrines, Institut J. Monod, Paris, France. A DNA fragment containing $800 \mathrm{bp}$ of the FRE1 promoter and the first $15 \mathrm{bp}$ of the coding sequence was cloned in the multicopy vectors YEp357 and YEp367 (Myers et al., 1986).

Cell growth, reductase assays and iron uptake. Cells were grown in liquid YNB-glucose medium (Yeast Nitrogen Base, Difco, $0.67 \%$, glucose $2 \%, \mathrm{w} / \mathrm{v})$ in aerobic conditions $(20 \mathrm{ml}$ medium in $100 \mathrm{ml}$ Erlenmeyer flask in a gyro-shaker at 200 r.p.m.). The culture media were treated with 8-hydroxyquinolein (Nicholas, 1957) prior to use to remove iron; $\mathrm{ZnSO}_{4}(1 \mu \mathrm{M})$ was added to the medium after hydroxyquinolein treatment. Residual iron in the treated media was estimated by inductively coupled plasma atomic emission spectroscopy. For the reductase assays, the cells were pre-cultured for $40 \mathrm{~h}$ at $30^{\circ} \mathrm{C}$, then washed twice with EDTA $(2 \%, w / v)$ and twice with distilled water. The cells were then inoculated to $\mathrm{OD}_{600} 0 \cdot 2$ (Kontron model Uvicon 860) into fresh culture medium, plus bathophenanthroline sulfonate (BPS; $200 \mu \mathrm{M}$ ), or different concentrations of iron [as $\mathrm{Fe}$ (III)-citrate].

The cells were grown for $8 \mathrm{~h}$ at $30^{\circ} \mathrm{C}$. Aliquots were withdrawn from the cultures every $2 \mathrm{~h}$, filtered and washed with water on nitrocellulose filters. The ferrireductase activity of the cells was measured with $\mathrm{Fe}$ (III)-citrate $(360 \mu \mathrm{M})$ as substrate (Lesuisse et al., 1987). Under these experimental conditions, the cell ferrireductase activity was maximum after 4-6 $\mathrm{h}$ of growth and then decreased. Only maximal values of ferrireductase activities are shown in the Results.

For iron uptake experiments, iron was added as $\left.{ }^{55} \mathrm{Fe}(\mathrm{III})\right]-$ citrate $(0 \cdot 1-1 \mu \mathrm{M})$ to either liquid YNB-glucose medium or solid YPG or YNB-glucose agar media. The cells were washed on the filters with $20 \mathrm{ml} \mathrm{Na} \mathrm{S}_{2} \mathrm{O}_{4}(1 \%$, w/v) and $20 \mathrm{ml}$ EDTA $(2 \%, \mathrm{w} / \mathrm{v}$, in $50 \mathrm{mM}$ citrate, $\mathrm{pH} 6.5)$.

Thiols assays. Total low-molecular-mass thiols and surface sulfhydryl groups were assayed with DTNB as previously described (Lesuisse \& Labbe, 1992).

\section{RESULTS}

\section{Effect of YAP genes on iron-limited growth}

Several reports (Schnell \& Entian, 1991; Wu et al., 1993; Bossier et al., 1993) have stated that overexpression of $Y A P 1$ or $C A D 1 / Y A P 2$ genes makes cells more resistant to the iron chelator 1,10 phenanthroline on agar plates. We confirmed this observation and tested the resistance of the cells to other hydrophobic and hydrophilic iron chelators, including bathophenanthroline, bathophenanthroline disulfonic acid (BPS), ferrozine, 2,2' bipyridyl, 8-hydroxyquinolein and 8-hydroxyquinolein disulfonic acid. All these molecules had nearly the same effect on the growth of all strains (wild-type, $\Delta y a p 1, \Delta c a d 1, \Delta y a p 1 \Delta c a d 1$, $Y A P 1$ overexpressed, $C A D 1$ overexpressed) on agar plates: for example, both 2,2'-bipyridyl and 8-hydroxyquinolein had a slight inhibitory effect at $150 \mu \mathrm{M}$ and fully inhibited the growth of all strains at $250 \mu \mathrm{M}$; BPS had a strong inhibitory effect on the growth of all strains at $1 \mathrm{mM}$ (data not shown). Schnell \& Entian (1991) previously reported that BPS did not lead to a YAP1dependent resistance phenotype and attributed this to the hydrophilic nature of the chelator, which is not believed to cross the cell membrane. But this seems unlikely, since the hydrophobic chelators 2,2 ' bipyridyl and 8-hydroxyquinolein had the same inhibitory effect on the growth of all the strains.

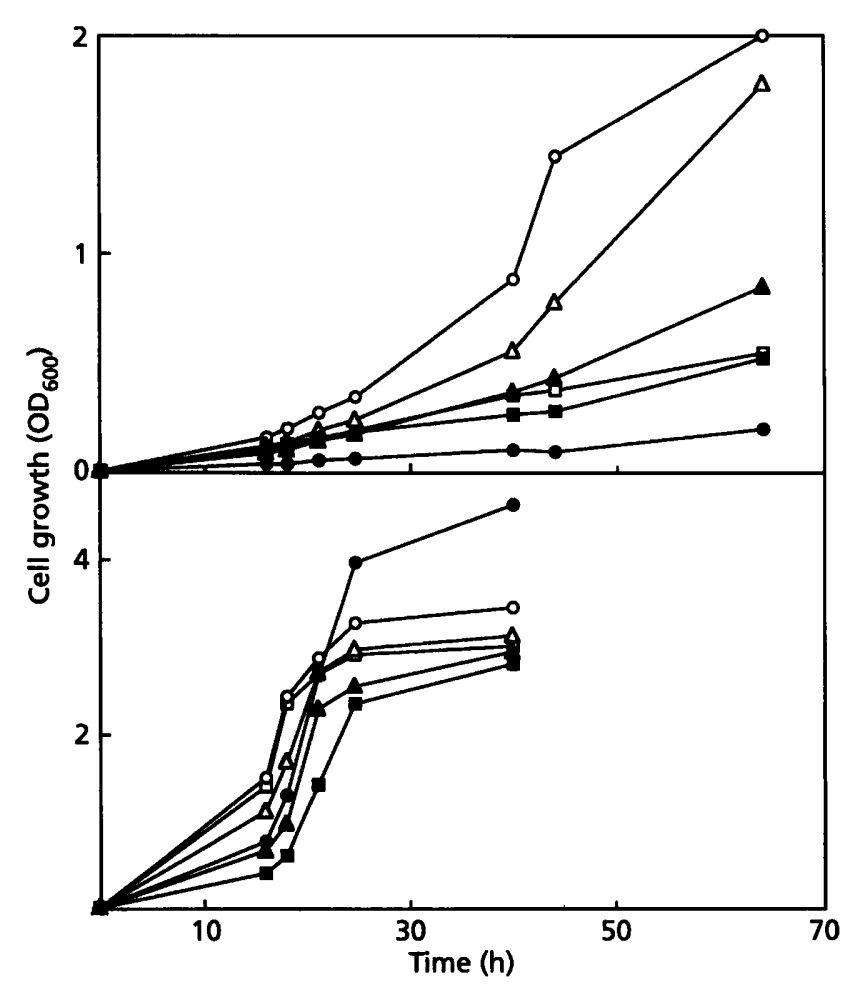

Fig. 1. Growth curves of different yeast strains under irondeficient (upper panel) or iron-sufficient (lower panel) conditions. Cells were inoculated to $O D_{600} 0.01$ in iron-deficient (YNB-glucose $+100 \mu \mathrm{M}$ BPS, upper panel) or iron-sufficient (YNB-glucose, lower panel) media. $\square$, Wild-type; $O, \Delta$ yap1; $\triangle, \Delta$ cad1; $\square$, $\triangle$ yap1 $\triangle$ cad1; O, YAP1 overexpressed; $\triangle, C A D 1$ overexpressed. 
Table 1. Effects of cadmium and iron on the growth of different yeast strains

Cells were patched on YPG-agar medium containing different amounts of cadmium and iron. The growth of the colonies was estimated after 1 week at $30^{\circ} \mathrm{C} .+++$, Normal growth; + , poor growth; - , no growth.

\begin{tabular}{|c|c|c|c|c|c|c|c|c|c|c|c|c|}
\hline $\begin{array}{l}{\left[\mathrm{Cd}^{2+}\right](\mu \mathrm{M}) \ldots} \\
{\left[\mathrm{Fe}^{3+}\right](\mu \mathrm{M}) \ldots}\end{array}$ & $\begin{array}{c}180 \\
10\end{array}$ & $\begin{array}{c}240 \\
10\end{array}$ & $\begin{array}{c}300 \\
10\end{array}$ & $\begin{array}{c}360 \\
10\end{array}$ & $\begin{array}{c}420 \\
10\end{array}$ & $\begin{array}{c}480 \\
10\end{array}$ & $\begin{array}{l}180 \\
10^{3}\end{array}$ & $\begin{array}{l}240 \\
10^{3}\end{array}$ & $\begin{array}{l}300 \\
10^{3}\end{array}$ & $\begin{array}{l}360 \\
10^{3}\end{array}$ & $\begin{array}{l}420 \\
10^{3}\end{array}$ & $\begin{array}{l}480 \\
10^{3}\end{array}$ \\
\hline Wild-type & ++ & + & + & - & - & - & +++ & +++ & +++ & +++ & ++ & ++ \\
\hline$\Delta y a p 1$ & + & - & - & - & - & - & +++ & $+t$ & + & + & + & + \\
\hline$\Delta c a d 1$ & ++ & + & + & - & - & - & +++ & +++ & ++ & ++ & ++ & ++ \\
\hline$\Delta y a p 1 \Delta c a d 1$ & - & - & - & - & - & - & ++ & - & - & - & - & - \\
\hline YEp351-YAP1 & +++ & +++ & +++ & +++ & +++ & ++ & +++ & +++ & +++ & +++ & ++ & ++ \\
\hline pAW18 & +++ & +++ & +++ & +++ & +++ & ++ & +++ & +++ & +++ & +++ & +++ & +++ \\
\hline
\end{tabular}

Table 2. Iron uptake by cells grown on agar plates

The agar medium (YPG) contained $1 \mu \mathrm{M}{ }^{55} \mathrm{Fe}$ (III)-citrate. After 1 week of growth at $30^{\circ} \mathrm{C}$, the cellular paste was suspended in water and cells were washed onto a filter with EDTA and dithionite. Iron uptake was determined by liquid scintillation counting of the solubilized samples.

\begin{tabular}{|c|c|c|c|c|}
\hline \multirow[t]{2}{*}{ Strain } & \multicolumn{4}{|c|}{ Iron uptake [pmol (mg wet wt cells) $\left.{ }^{-1}\right]$} \\
\hline & No addition & $\mathrm{Cd}^{2+}(60 \mu \mathrm{M})$ & $\mathrm{Cd}^{2+}(120 \mu \mathrm{M})$ & BPS $(100 \mu \mathrm{M})$ \\
\hline Wild-type & $22 \cdot 5$ & $7 \cdot 5$ & $3 \cdot 8$ & $3 \cdot 7$ \\
\hline$\Delta y a p 1$ & $23 \cdot 2$ & $4 \cdot 5$ & $3 \cdot 8$ & $4 \cdot 5$ \\
\hline$\Delta c a d 1$ & $17 \cdot 3$ & $6 \cdot 7$ & $3 \cdot 0$ & $3 \cdot 7$ \\
\hline$\Delta y a p 1 \Delta c a d 1$ & $19 \cdot 5$ & $4 \cdot 5$ & $3 \cdot 0$ & $2 \cdot 6$ \\
\hline YEp351-YAP1 & $21 \cdot 0$ & $7 \cdot 5$ & $3 \cdot 8$ & $5 \cdot 7$ \\
\hline pAW18 & $20 \cdot 2$ & $7 \cdot 5$ & $4 \cdot 8$ & 3.7 \\
\hline
\end{tabular}

The situation was different when the cells were grown in liquid medium (YNB-glucose). The $\Delta y a p 1$ mutant then had the highest growth rate and the YAP1-overexpressing strain had the lowest growth rate when the medium was supplemented with $100 \mu \mathrm{M}$ BPS (Fig. 1). Thus, overexpression of $Y A P 1$ did not favour the growth of cells in iron-deficient conditions as was suggested by Bossier $e t a l$. (1993). It resulted rather in an increased inhibition of growth on iron-deficient liquid medium (Fig. 1). This effect could not be related to differences in the ability of the strains to take up iron from the iron-deficient medium, as shown by the following experiment: wild-type, $\Delta y a p 1$ and $Y A P 1$-overexpressing strains were grown on either iron-sufficient (YNB-glucose) or iron-deficient medium (YNB-glucose $+100 \mu \mathrm{M}$ BPS) to which $0.25 \mu \mathrm{M}{ }^{55} \mathrm{Fe}$ (as $\mathrm{Fe}(\mathrm{III})$-citrate) was added. The amount of iron taken up by the cells was measured after $24 \mathrm{~h}$. No significant differences were observed between the strains when grown on either iron-sufficient medium [the three strains accumulated $15-20 \mathrm{pmol}$ iron (mg wet wt cells) ${ }^{-1}$ ] or iron-deficient medium [the three strains then accumulated 4-6 pmol iron (mg wet wt cells $\left.)^{-1}\right]$. Curiously, the growth defect in iron-deficient conditions of the $Y A P 1$-overexpressing strain was alleviated by adding the oxidative agent menadione disulfonate $(25-100 \mu \mathrm{M})$ to the medium. For example, after $4 \mathrm{~d}$ of growth in iron-deficient conditions (YNB-glucose medium $+100 \mu \mathrm{M}$ BPS, inoculated to $\mathrm{OD}_{600} 0.05$ ), that strain reached $\mathrm{OD}_{600} 0.8$ (versus 0.3 for the control culture) when the medium was supplemented with $25 \mu \mathrm{M}$ menadione disulfonate. In the same conditions, the wild-type reached $\mathrm{OD}_{600} 1 \cdot 7$ (versus 1.3 for the control culture). Again, this effect did not result from a difference in the amount of iron accumulated by the cells, since menadione disulfonate had no significant effect on the total iron taken up by the cells (data not shown).

\section{Cadmium toxicity and iron metabolism}

Wu \& Moye-Rowley (1994) showed that transcriptional activation of GSH1 - the first gene of glutathione biosynthesis - mediated by yAP1 is essential for normal cadmium tolerance in $S$. cerevisiae. However other factors seem involved in cadmium resistance/toxicity. As shown in Table 1, the cadmium resistance of the cells increased when the growth medium contained excess iron [Fe(III)citrate]. This effect was specific to iron since it was not observed when excess copper, or citrate alone, was added to the medium (data not shown). The effect of iron depended on the copy-number of $Y A P 1$ and $C A D 1$ genes. For example, it was less pronounced in the $\Delta y a p 1$ $\Delta$ cad1 mutant (Table 1). Analysis of the iron content of 


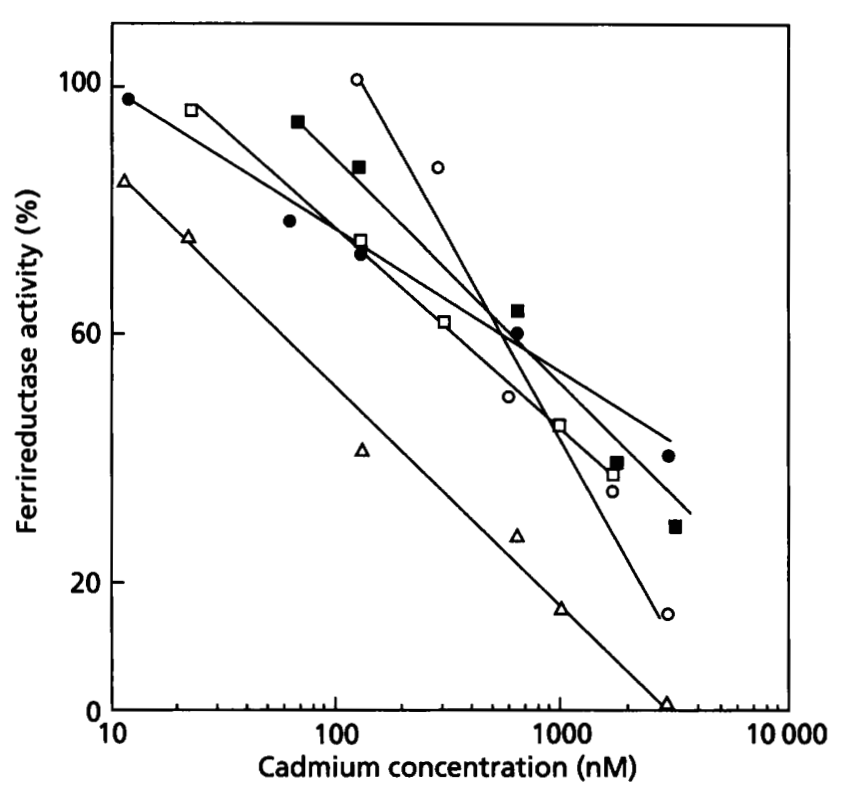

Fig. 2. Effect of cadmium concentration in the growth medium on the ferrireductase activity. Cells from $40 \mathrm{~h}$ pre-cultures were grown in liquid medium (previously treated with 8hydroxyquinolein) containing different concentrations of $\mathrm{CdSO}_{4}$. The ferrireductase activity of the cells was measured after 5 h of growth. $\square$, Wild-type; $\square, \Delta$ yap1; $\triangle, \Delta$ cad1; $O$, YAP1 overexpressed; O, CAD1 overexpressed. Values, expressed as percentage of maximal activity (in the absence of added cadmium), are means of 3-5 experiments.

cells grown on agar plates with or without added cadmium showed that iron uptake decreased in the presence of cadmium (Table 2). At a cadmium concentration of $120 \mu \mathrm{M}$, the iron content of the cells was roughly similar to that of cells grown in the presence of $100 \mu \mathrm{M}$ of the iron chelator BPS (Table 2). When the cells were grown in liquid medium, their iron content began to decrease when the extracellular cadmium concentration reached $1 \mu \mathrm{M}$ (not shown). At low extracellular cadmium concentrations $(1-10 \mu \mathrm{M})$, only the wild-type strain and the $\Delta y a p 1, \Delta c a d 1$ and $\Delta y a p 1 \Delta c a d 1$ mutants showed a significant decrease of their intracellular iron pool. The iron contents of these cells in the presence of $10 \mu \mathrm{M}$ cadmium were $65 \%$

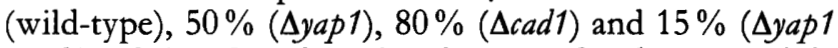
$\Delta$ cad1) of that found in the absence of cadmium, while $Y A P 1$ - and $C A D 1$-overexpressing strains were not affected.

Further investigations showed that cadmium had a strong repressive effect on the ferrireductase activity of the cells (Fig. 2). When added during the reductase assays, this metal showed no direct inhibitory effect on the ferrireductase activity of the cells (not shown). The inhibitory effect of cadmium was observed when $\mathrm{Cd}^{2+}$ was present during growth: the ferrireductase activity of the wildtype grown in iron-limited conditions ( $\leqslant 0.1 \mu \mathrm{M} \mathrm{Fe})$ was decreased by $50 \%$ when $1 \mu \mathrm{M}$ cadmium was added to the growth medium (Fig. 2). Again, the effect of cadmium depended on the $Y A P 1$ and $C A D 1$ gene activities: overexpression of $Y A P 1$ resulted in a steeper inhibition

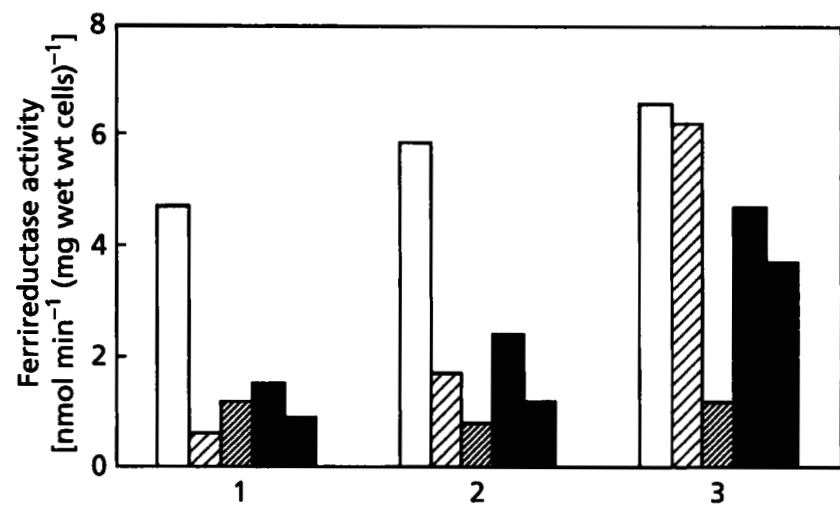

Fig. 3. Effect of growth medium iron concentration on ferrireductase activity of different yeast strains. Cultures were grown as described in Methods in YNB-glucose medium (treated with 8-hydroxyquinolein) supplemented with either $200 \mu \mathrm{M}$ BPS ( $\square$, iron-deficient conditions) or 0.1-200 $\mu \mathrm{M}$ Fe(III)citrate $(\square, 0.1 \mu \mathrm{M} ; 0,2 \mu \mathrm{M} ; \square, 20 \mu \mathrm{M} ; \square, 200 \mu \mathrm{M})$. Cells were grown for $5 \mathrm{~h}$, harvested, washed, and their ferrireductase activity was measured. 1, Wild-type; $2, \Delta y a p 1 ; 3, \Delta$ cad1. Data are means $\pm S E$ of four experiments.

curve, while overexpression of $C A D 1$ lead to the opposite effect (Fig. 2). Disruption of $Y A P 1$ had little effect, while disruption of $C A D 1$ caused the cell ferrireductase to be 10 -fold more sensitive to the effect of cadmium (50\% inhibition at $0 \cdot 1 \mu \mathrm{M}$ ) than the wild-type (Fig. 2).

\section{Effect of YAP genes on ferrireductase activity}

The ferrireductase activity of the cells in the absence of added cadmium was also affected by the $Y A P 1$ and $C A D 1$ gene contents. The effects of $Y A P 1$ and $C A D 1$ on the cell ferrireductase depended greatly on the experimental conditions (pre-culture and culture; data not shown), and varied according to the iron content of the growth medium (Fig. 3). The ferrireductase activity of the wild-type was maximum when cells were grown in irondeficient conditions ( $200 \mu \mathrm{M}$ BPS), and then dropped when iron was added. However, the decrease in ferrireductase activity was not strictly proportional to the concentration of iron added (Fig. 3). The greatest decrease occurred at $0.1 \mu \mathrm{M}$ iron and there was a reproducible small peak of activity at 2-20 $\mu \mathrm{M}$ iron. The $\Delta y a p 1$ strain showed maximal repression at an iron concentration of $2 \mu \mathrm{M}$, and a well-marked peak of activity at $20 \mu \mathrm{M}$ iron (Fig. 3). The ferrireductase activity of the $\Delta$ cad1 strain remained almost fully induced when iron was $0 \cdot 1 \mu \mathrm{M}$, and decreased sharply around $2 \mu \mathrm{M}$ (Fig. 3). Two genes - FRE1 (Dancis et al., 1992) and FRE2 (Georgatsou \& Alexandraki, 1994) - have so far been identified as playing a direct role in cell ferrireductase activity. Both genes probably encode plasma membrane structural components of the reductase system(s). To see whether FRE1 could be transcriptionally regulated by yAP1 and/or CAD1, the strains used in this study were transformed by a multicopy plasmid bearing the lac $Z$ coding sequence fused to the FRE1 promoter. $\beta$-Galactosidase activity was determined in 
Table 3. Ferrireductase activity, surface thiols and intracellular low-molecular-mass thiols associated with cells of different strains

Cells were grown for $5 \mathrm{~h}$ in YNB-glucose medium (treated with 8-hydroxyquinolein) supplemented with either $200 \mu \mathrm{M}$ BPS $(-\mathrm{Fe})$ or $0 \cdot 1 \mu \mathrm{M} \mathrm{Fe}(\mathrm{III})$-citrate $(+\mathrm{Fe})$. The cell ferrireductase activity was measured as described in Methods. The thiol groups (intracellular and surface) were assayed with DTNB after incubation of the washed cells for $3 \mathrm{~min}$ in citrate buffer $(50 \mathrm{mM}, \mathrm{pH} 6.5)$ containing $5 \%$ glucose. Values are expressed in $\mathrm{nmol}\left(\mathrm{mg}\right.$ wet wt cells) ${ }^{-1}$.

\begin{tabular}{|c|c|c|c|c|}
\hline Strain & $\begin{array}{l}\text { Growth } \\
\text { condition }\end{array}$ & $\begin{array}{l}\text { Ferrireductase } \\
\text { activity (nmol } \\
\left.\min ^{-1} \mathbf{m g}^{-1}\right)\end{array}$ & $\begin{array}{l}\text { Surface thiols } \\
\left(\mathrm{nmol} \mathrm{m} \mathrm{m}^{-1}\right)\end{array}$ & $\begin{array}{l}\text { Intracellular thiols } \\
\left(\mathrm{nmol} \mathrm{mg}^{-1}\right)\end{array}$ \\
\hline Wild-type & $-\mathrm{Fe}$ & $3 \cdot 8$ & 0.8 & $3 \cdot 5$ \\
\hline Wild-type & $+\mathrm{Fe}$ & 0.5 & 0.2 & $2 \cdot 7$ \\
\hline syap1 & $-\mathrm{Fe}$ & $5 \cdot 3$ & 0.9 & $2 \cdot 6$ \\
\hline Syap1 & $+\mathrm{Fe}$ & $2 \cdot 2$ & 0.5 & $1 \cdot 6$ \\
\hline$\Delta c a d 1$ & $-\mathrm{Fe}$ & $6 \cdot 5$ & $1 \cdot 2$ & $4 \cdot 7$ \\
\hline$\Delta c a d 1$ & $+\mathrm{Fe}$ & $7 \cdot 0$ & $1 \cdot 3$ & $4 \cdot 7$ \\
\hline
\end{tabular}

each strain grown under the conditions described above. The results showed that yAP1 and CAD1 had no direct influence on FRE1 transcription. $\beta$-Galactosidase activity was induced by iron-deprivation (+ BPS; $1500-2000 \mathrm{U} \beta$ galactosidase) in all strains tested and was strongly repressed when iron $(0 \cdot 1-200 \mu \mathrm{M})$ was added to the culture medium (100-300 U, data not shown).

An indirect influence of $Y A P / C A D$ genes on ferrireductase activity could theoretically be exerted via modulation of the cell redox status. Therefore, we measured the intracellular low-molecular-mass thiols and the surface sulfhydryl groups in different strains grown in different conditions (Table 3). The level of reduced thiols was previously shown to be increased in iron-deprived cells (Lesuisse \& Labbe, 1992). As shown in Table 3, this was again observed here. Interestingly, we found a constant relationship between the ferrireductase activity of the cells - whatever the strain - and the amount of surface sulfhydryl groups accessible to the membrane-impermeant Ellman's reagent (DTNB) (Table 3). For example, the $\Delta c a d 1$ strain, which showed unrepressed ferrireductase activity when grown with $0.1 \mu \mathrm{M}$ iron, also showed the highest level of reduced surface thiols and of intracellular low-molecular-mass thiols under this growth condition (Table 3). The $\Delta y a p 1$ strain which is expected to have a lower glutathione pool than the wild-type (Wu \& MoyeRowley, 1994) showed indeed a lower content of intracellular reduced thiols, but was unaffected in its surface thiol pool and similarly unaffected in its ferrireductase activity (Table 3 ).

\section{DISCUSSION}

An excess of iron in the growth medium makes the cells more resistant to cadmium; reciprocally, cadmium inhibits ferrireductase activity and iron uptake. Thus, while cadmium tolerance is mainly a function of the $Y A P 1$ and $C A D 1$ gene activity - probably via modulation by these genes of glutathione synthesis (see Wu \& Moye-Rowley, 1994) - the toxicity of cadmium could at least partly be linked to the defects in iron metabolism induced by this metal.

The dosage of $Y A P 1$ and $C A D 1 / Y A P 2$ genes has a marked effect on the ability of cells to grow in irondeficient medium, on ferrireductase activity and on the rate of ferrireductase repression by cadmium. On YPGagar medium, $Y A P$-overexpressing cells were more resistant than wild-type cells to 1,10-phenanthroline, but not to other iron chelators. We believe that the resistance to 1,10-phenanthroline is relevant to a detoxification process, which could be less effective with other chelators like 2,2 '-bipyridyl or 8 -hydroxyquinolein. The growth of $Y A P 1$-overexpressing cells on iron-deficient liquid medium was strongly inhibited. Possibly, the YAP1overexpressing cells grown in such conditions could suffer from an imbalance of their redox status, more than from a lack of iron sensu stricto, since overexpression of YAP1 is known to result in an increase of the intracellular glutathione pool (Grey \& Brendel, 1994). The growth of cells in iron-deficient conditions also results in a significant increase in the intracellular and surface reduced thiol pools (Lesuisse \& Labbe, 1992). According to this hypothesis, menadione would alleviate the growth defect by shifting the cell redox balance towards a more oxidized state. It should be pointed out that identical conditions of growth cannot be reproduced on agar plates, since agar medium cannot be treated by 8-hydroxyquinolein.

The $Y A P$ gene products could theoretically act on ferrireductase activity at several levels. The FRE1 and FRE2 genes contain ARE-resembling elements in their promoter regions and could then be candidates for transcriptional regulation by yAP1 and/or CAD1. The FRE1 gene contains the sequence TTTTTGCTCAYC at positions -267 and -284 from ATG. Dancis et al. (1992) showed that this repeated sequence could constitute a candidate binding site for an iron-responsive regulatory 
protein. The FRE2 gene also contains ARE-resembling elements at positions -306 (TGGCTCA) and -489 (GTGACTC) from ATG. The influence of $Y A P$ genes on ferrireductase activity does not seem to be exerted via transcriptional regulation of FRE1. However, yAP1 and/or CAD1 could regulate transcription of other genes encoding other structural components and/or regulatory components of the reductase system(s) (FRE2 or some still-unidentified component). yAP1 and/or CAD1 could also influence the ferrireductase activity of the cells indirectly, by acting on genes involved in the posttranscriptional regulation of reductase activity. YAP1, for example, appears to play an important role in the oxidative stress response of $S$. cerevisiae (Kuge \& Jones, 1994). Since the ferrireductase activity of the cells also seems to be related to their redox status (Lesuisse \& Labbe, 1992), yAP1 (and/or CAD1) may have an indirect effect on ferrireductase activity at several levels, such as glutathione synthesis (Wu \& Moye-Rowley, 1994), glutathione reductase and/or glucose-6-phosphate dehydrogenase activities (Schnell et al., 1992). The products of $Y A P 1$ and/or $C A D 1$ genes could also act on the reductase activity via the RAS/cAMP pathway. Previous work (Lesuisse et al., 1991) suggested that a cAMPmediated activation of protein kinase A could be needed to fully derepress ferrireductase activity. Gounalaki \& Thireos (1994) showed that there is a link between transcriptional activation by yAP1 of TPS2 (encoding trehalose phosphate phosphatase) and the activity of cAMP-regulated protein kinase. It is worth noting that FRE1 shows significant homologies with one component of the neutrophil NADPH oxidase system (Dancis et al., 1992), the activity of which is partly regulated by phosphorylation/dephosphorylation. Nothing is presently known about the post-transcriptional regulation of the yeast ferrireductase system(s). Recent studies suggest the existence of complex inter-connections between the metabolisms of iron and copper (Dancis et al., 1994) and the metabolic pathways involved in the response to oxidative stress (see for example the phenotype of mac1 mutants; Jungmann et al., 1993). We believe that cell ferrireductase activity is regulated at several levels involving not only the iron and copper contents of the cells but also the cell redox status - which in turn is related to the iron/copper status - as a function of the growth phase and of the extracellular redox conditions. The adaptative role of $Y A P 1$ and $C A D 1 / Y A P 2$ genes in relation to iron metabolism remains to be defined in that complicated background.

\section{ACKNOWLEDGEMENTS}

We thank DrW. S. Moye-Rowley for the yeast strains and plasmids and Dr O. Parkes for checking the manuscript.

\section{REFERENCES}

Bossier, P., Fernandes, L., Rocha, D. \& Rodrigues-Pousada, C. (1993). Overexpression of $Y A P 2$, coding for a new yAP protein, and $Y A P 1$ in Saccharomyces cerevisiae alleviates growth inhibition caused by 1,10-phenanthroline. J Biol Chem 268, 23640-23645.
Dancis, A., Klausner, R. D., Hinnebusch, A. G. \& Barricanal, J. G. (1990). Genetic evidence that ferric reductase is required for iron uptake in Saccharomyces cerevisiae. Mol Cell Biol 10, 2294-2301.

Dancis, A., Roman, D. G., Anderson, G. J., Hinnebusch, A. G. \& Klausner, R. (1992). Ferric reductase of Saccharomyces cerevisiae: molecular characterization, role in iron uptake, and transcriptional control by iron. Proc Natl Acad Sci US A 89, 3869-3873.

Dancis, A., Yuan, D., Haile, D., Askwith, C., Eide, D., Moehle, C., Kaplan, J. \& Klausner, R. (1994). Molecular characterization of a copper transport protein in S. cerevisiae: an unexpected role for copper in iron transport. Cell 76, 393-402.

Eide, D., Davis-Kaplan, S., Jordan, I., Sipe, D. \& Kaplan, J. (1992). Regulation of iron uptake in Saccharomyces cerevisiae. J Biol Chem 267, 20774-20781.

Georgatsou, E. \& Alexandraki, D. (1994). Two distinctly regulated genes are required for ferric reduction, the first step of iron uptake in Saccharomyces cerevisiae. Mol Cell Biol 14, 3065-3073.

Gounalaki, N. \& Thireos, G. (1994). Yap1p, a yeast transcriptional activator that mediates multidrug resistance, regulates the metabolic stress response. EMBO J 13, 4036-4041.

Grey, M. \& Brendel, M. (1994). Overexpression of the SNQ3/YAP1 gene confers hyper-resistance to nitrosoguanidine in Saccharomyces cerevisiae via a glutathione-independent mechanism. Curr Genet 25, 469-471.

Harshman, K. D., Moye-Rowley, W. S. \& Parker, C. S. (1988). Transcriptional activation by the SV40 AP-1 recognition element in yeast is mediated by a factor similar to AP-1 that is distinct from GCN4. Cell 53, 321-330.

Jungmann, J., Reins, H. A., Lee, J., Romeo, A., Hassett, R., Kosman, D. \& Jentsch, S. (1993). MAC1, a nuclear regulatory protein related to $\mathrm{Cu}$-dependent transcription factors is involved in $\mathrm{Cu} / \mathrm{Fe}$ utilization and stress resistance in yeast. EMBO $J 12$, 5051-5056.

Kuge, S. \& Jones, N. (1994). YAP1 dependent activation of TRX2 is essential for the response of Saccbaromyces cerevisiae to oxidative stress by hydroperoxides. EMBO J 13, 655-664.

Lesuisse, E. \& Labbe, P. (1992). Iron reduction and trans-plasma membrane electron transfer in the yeast Saccharomyces cerevisiae. Plant Pbysiol 100, 769-777.

Lesuisse, E., Raguzzi, F. \& Crichton, R. (1987). Iron uptake by the yeast Saccharomyces cerevisiae : involvement of a reduction step. J Gen Microbiol 133, 3229-3236.

Lesuisse, E., Horion, B., Labbe, P. \& Hilger, F. (1991). The plasma membrane ferrireductase of Saccharomyces cerevisiae is partially controlled by cylic AMP. Biochem J 280, 545-548.

Lesuisse, E., Simon, M., Klein, R. \& Labbe, P. (1992). Excretion of anthranilate and 3-hydroxyanthranilate by Saccharomyces cerevisiae: relationship to iron metabolism. J Gen Microbiol 138, 85-89.

Moye-Rowley, W. S., Harshman, K. D. \& Parker, C. S. (1989). Yeast $Y A P 1$ encodes a novel form of the jun family of transcriptional activator proteins. Genes \& Dev 3, 283-292.

Myers, A. M., Tzagoloff, A., Kinney, D. M. \& Lusty, C. J. (1986). Yeast shuttle and integrative vectors with multiple cloning sites suitable for construction of lac $Z$ fusions. Gene 45, 299-310.

Nicholas, D. J. D. (1957). Microbiological methods for determining magnesium, iron, copper, zinc, manganese and molybdenum. Methods Enzymol 3, 1035-1041.

Schnell, N. \& Entian, K. D. (1991). Identification and characterization of a Saccharomyces cerevisiae gene (PAR1) conferring resistance to iron chelators. Eur J Biochem 200, 487-493. 
Schnell, N., Krems, B. \& Entian, K. D. (1992). The PAR1 (YAP1/SNQ3) gene of Saccharomyces cerevisiae, a c-jun homologue, is involved in oxygen metabolism. Curr Genet 21, 269-273.

Wu, A. \& Moye-Rowley, W. S. (1994). GSH1, which encodes $\gamma$ glutamylcysteine synthetase, is a target gene for yAP-1 transcriptional regulation. Mol Cell Biol 14, 5832-5839
Wu, A., Wemmie, J. A., Edgington, N. P., Goebl, M., Guevara, J. L. \& Moye-Rowley, W. S. (1993). Yeast bzip proteins mediate pleiotropic drug and metal resistance. J Biol Chem 268, 18850-18858.

Received 11 May 1995; revised 27 June 1995; accepted 24 July 1995. 